\title{
Comparative Research of feminist content on Tiktok and Weibo
}

\author{
Name: Yurong Cui
}

\author{
Author Affiliation: The University of Sydney
}

Email: ycui6351@uni.sydney.edu.au

\begin{abstract}
As educational equality becomes more accepted, females have gained a prominent on more societal responsibilities and get some chance to voice. However, females suffer difficulty in ensuring the same advantages as males and achieving a vital role in the courts and public administration. Particularly in some developing countries, mothers are indeed regarded to be tied to their households. The Internet has created a "speaking" culture based on this sociological trend, enabling an international feminist community and empowering feminists to become a trendy topic in today's society (Munro, 2013). ${ }^{[18]}$ The wave of feminism, which engages in online and in-person engagements, has progressively grown, with the \#MeToo campaign being the most prominent example. Making individuals aware of gender bias in community interaction beneath patriarchy through the spread of information has been one of the motivating causes and motives for the growth of feminism, prompting more constitutional protections activities, including fighting gender inequality, bullying on the street, and violence against women (Flores et al., 2020). ${ }^{[5]}$

The emergence of social media channels has opened up more opportunities for feminism to flourish. This intuitive data transmitted, and user interactions have ensured that worldwide feminist knowledge is connected. This suggests that females have more voice and that anyone may advocate for feminism. Simultaneously, advancements in mobile device technology have made it simpler for users to explore applications on their phones; those apps readily propagate various and customized feminist ideals by linking various groups (Locke et al., 2018). ${ }^{[13]}$ As two of the most well-known instances, Weibo and Tiktok have a substantial number of videos and written descriptions encouraging moderation and radical feminism. Consumers with a significant following, such as @ thedebralea, @manishajhingoer, and @ rovi-wade on Tiktok and @Xingbieshuibot, @Takaniiiher and @SoniaWangs on Weibo, propagate feminist ideas by posting videos and talking with their fans. Some feminism hashtags, such as \#momsofttiktok and \#girlshelpgirl, are often used to draw attention to specific posts. The majority of these users are young women waking to gender consciousness and creating a new kind of rights protection by sharing their personal experiences, making feminism more visible (Rich, 2005). ${ }^{[20]}$ The approach and substance of promoting feminist ideals are similar and different in these two apps.
\end{abstract}

Keywords: Feminism, Radical feminism, Moderate feminism, Weibo, TikTok

\section{INTRODUCTION}

Radical feminism is increasingly onto the historical arena in this setting. According to Graham (1994), radical feminism is the radical evolution of liberal feminists in the modern century. ${ }^{[6]}$ In this context, radical feminism is making inroads into the historical arena. Graham (1994) defines radical feminism as the extreme development of liberal feminists inside the 20th century. ${ }^{[6]}$ Radical feminism originated from some female sexual dissatisfaction with the Current Left revolution's violent approach of males, as well as their discontent with the typical behavior of female's groups in the U.S. Its influence moved from Boston And New York to the rest of the United States and Europe during the 1960s and 1970s (Vukoičić, 2017). [26] Radical feminism opposes patriarchal tyranny and female maltreatment tries to prevent male-dominated society and is dedicated to researching females' everyday life such as menstruation, childbearing, housekeeping, incredibly satisfying male sexual desires (Lorber, 1997). ${ }^{[14]}$ Mackay (2015a) indicated that radical feminists argue that male rights constrain and threaten women's self-esteem and inventiveness, emphasizing 
subversive and threatening women's entire groups by men in addition to their attention on male aggression. ${ }^{[15]}$ According to Mackay (2015b), extreme feminism might be considered irrational feminism since it is a fringe element that

criticizes males as the primary thought, resulting in discrimination and anti-feminist sentiment. ${ }^{[16]}$ Another aspect of postfeminism is younger women's disagreement with feminists; to a certain extent, this enlarges feminist theory in political activity and geographical scope. According to Roy (2013), "moderateness" appears to have good analytical potential in current feminist discourses. ${ }^{[23]}$ Moderate feminism often displays itself in the growth of postfeminism and neoliberalism by diminishing and debunking feminist activities and addressing reformism in left-wing political ideology. The radical feminist theory substitutes original understanding with an alternative value and an offensive on experience, displaying a utopian vision, continually influencing liberal feminists and giving the movement a "poor image" (Bouchier, 1979). ${ }^{[3]}$ Roy (2013) illustrates that compared to radical feminism, which is committed to freedom and individuality, moderate feminism is softer and acknowledges gender distinctions, as seen by criticizing or even demeaning extreme feminism. ${ }^{[23]}$

The advent of the Internet having sped its transition from the "third wave" to the "fourth wave" among feminism, and femininity has now been regularly argued in online organizations (Munro, 2013) ${ }^{[18]}$ Feminism, which originated from social networking sites such as Facebook and Twitter, sparked the fourth wave feminism (Rivers, 2017). ${ }^{[21]}$ Weibo is known as "China's Twitter" for debating topics and headlines, and it has grown into a discussion board for Asian women could debate as well as help change in society in this setting, offering local feminists with a new bottom-up activism approach that contrasts from the standard top perspective (Lixian, 2015). ${ }^{[12]}$ Similarly, Weibo, a Chinese social networking site, has spread a form of "pastoral/rural feminism," which definition is one-sided attribution of gender imbalance to men, demonstrating radical feminism's characteristics (Mao, 2020). ${ }^{[17]}$ Tiktok first gained popularity in China, then in the United States, eventually being one of the most popular smartphone apps for distributing "cultural commodities" by sharing short movies ranging from fifteen to sixty seconds (Kaye et al., 2021). ${ }^{[10]}$ Tiktok video material has a viral format owing to the platform's distinctive algorithms and labeled media distribution, permitting the fourth wave feminism concerns sexually liberty, body acceptance, and feminine ambition to reach far more consumers with its particular representation (Rebecca \& Stefanie, 2021). [19]

Western feminist study and development have progressed through a historic development cycle, from discipline movements to modern culture and mainstream media studies. Yuemin ( 2008 ) shows the western women's rights movement has gone through multiple stages, including "liberal feminism," "socialist feminism," "radical feminism," and "postmodern feminism." [29] As a result, western women are more sensitive to gender issues. Women's educational and earnings levels in China have improved dramatically since the 1980s, and their higher socioeconomic situation has progressively allowed women to obtain autonomy in the home and society ( $\mathrm{Wu}, 2014) .{ }^{[27]}$ Unlike in the Western, when China built an economic system, there was an inclination to embrace consumer culture, which reduced the public's judgement on gender inequality, causing most Chinese women to perceive feminism as one-sided, aligning with males and requiring women to work. On the other hand, after thousands of years of being influenced by Confucian culture, the gender notion in Chinese culture seems to be more moderate than those in the West, and their place in the household is more uncertain (Yuemin, 2008). ${ }^{[29]}$ This has resulted in disparities in the distribution of feminist information between both two sites.

\section{RESEARCH QUESTION}

This study compares and evaluates the popular posts of some fashionable members on Weibo and Tiktok in order to investigate the characteristics of radical feminism and moderate feminism.

\section{METHODOLOGY}

This study will conduct qualitative research method utilizing the content analysis methodology to define the perceived distributed material clearly, systematically, and numerically (Bengtsson, 2016). ${ }^{\text {[2] }}$ The quantitative method findings are based on accurate and accessible practical truths, expressed in precise proportions, standards, and analyzed figures. In contrast to quantitative analysis, qualitative analysis examines the values and thinking of the information through explanation, critique, and assessment (Greetham, 2009). ${ }^{[7]}$ The primary research methodologies of this study are the qualitative and quantitative data gathering methods for Weibo and TikTok. The assignment uses the quantitative data collection technique to explore and monitor Weibo and TikTok videos and comments. The comparative study of the two platforms' content will be adequately provided and rationally in the table form, and the chi-square testing technique will be used to investigate the comparison between the two platforms' materials statistically. Using qualitative research, describe the feminism contents of these two platforms in the context of their distinct cultural background and extant literature and ideas. Simultaneously, the relevant ideals and cultural context, complete with issues and inconsistencies, will be conveyed. Hundreds of videos and comments on moderate feminism and radical 
feminism will be collected for comparative analysis utilizing concepts and tables in this project.

\section{RESULTS}

This research explored bloggers' videos, primarily on Weibo and TikTok, as instances of moderate feminism and the substance of remarks made in reaction to those videos as examples of radical feminism.

\section{1. moderation feminism}

218.3k followers follow @ @thedebralea on Tiktok, with $530.2 \mathrm{k}$ likes and $132.1 \mathrm{k}$ comments on her video "my opinion on contemporary feminism." This video's main aim is to criticize extreme feminism. She feels that today's women do not desire equality, but rather to be men. With 293,000 followers, @ SoniaWangs is a Weibo star. Her feminism-themed Weibo videos have sixty thousand views, six hundred and ninety-four likes, sixty comments, and forty-six reposts. She acknowledges feminism through individual perspective as much as tangible evidence. She identified five aspects about feminism in her video: Women wield more power within their own homes; Females in Jiangsu, Zhejiang, and Shanghai seem to be more self-sufficient than in Guangzhou; Criticism of fan comments since money does not really govern reproductive suffrage and mothers may be feminists as well; In the Chaoshan area, male harassment of women is a product of patriarchal society; Improper marriage legislation.

The table 1 examines the substance and consistency of feminist viewpoints in two videos. These two videos have a statistical time of 28.10.2021.

Table 1 Content Type comparative

\begin{tabular}{|c|c|c|}
\hline Content Type & TikTok (\%) & Weibo (\%) \\
\hline Masculine females & 57 & 29 \\
\hline Patriarchal & 14 & 29 \\
\hline Housework & 14 & 14 \\
\hline Work & 14 & 29 \\
\hline
\end{tabular}

Figure 1 illustrates that the two platforms are not statistically significant in "Content Type" because there seems to be no difference in the distribution of "Content Type" between media.

\begin{tabular}{lcccc}
\hline & \multicolumn{2}{c}{ Platform $(\mathrm{N}, \%)$} & $\chi 2$ & $\mathrm{P}$ \\
\cline { 2 - 3 } & TikTok & Weibo & & \\
\hline $\begin{array}{l}\text { Content } \\
\text { Type }\end{array}$ & & & 1.33 & 0.72 \\
Masculine & $4(57.1)$ & $2(28.6)$ & & \\
females & & & \\
Patriarchal & $1(14.3)$ & $2(28.6)$ & & \\
Housework & $1(14.3)$ & $1(14.3)$ & \\
Work & $1(14.3)$ & $2(28.6)$ & \\
\hline
\end{tabular}

Figure 1 Content Type comparative

The two bloggers have one commonality: they simultaneously tackle feminism-related topics including machismo, patriarchy, housework, and female labor. Moreover, they all resist radical feminists, respect for women staying in the house, and resist women purposely imitating males. While contrasted to more impartial responses on Weibo videos, including males and females using their distinct personality traits to share work and collaborate, TikTok's videos are more antagonistic to radical feminism. Women's criticisms against masculinity, in particular, account for 57percentage points of all statements and are much more prone to urge women to take up their womanhood and rejoin the domestic.

\subsection{Radical feminism}

Many users responded on @ thedebralea's video, writing, "All of this garbage about standards of beauty and motherhood is basically you are imposing your perspective about how to live a good life and calling everyone who opposes as a Feminism." "Why how can you be so concerned to what other females do?" It's their way of life, and you can't make their mind up for them. Allow individuals to do what appears to be good for themselves." "Girls cannot determine the standards due to patriarchal cultural systems." You, like men, are a product of patriarchy." "You undoubtedly feel that ladies must not be paid fairly and therefore it is worthless for a girl to attend university and acquire a diploma", "You will know you said the incorrect thing when you see guys clapping and agreeing with you", "Which chapter of the maids tale is this?" "It's unsettling to hear misogyny of you. This video is stupid, and you should have a more important aim than being chosen love." SoniaWangs referenced radical feminist information shared by netizens on her Weibo in her video. "Feminist movement is the financial liberty of females; this has nothing to do with males and therefore should be divorced from men," the contents state. "The entire society does not consider a 
housewife to be a feminist since she is raised by others." Some extreme feminist viewpoints on feminism could be discovered in some other Weibo remark by @SoniaWangs, such as "males need gene recombination", "men merely have compassion for males", "Have no illusions about men" and "Husband and wife are sometimes considered as two species, at least in terms of the distinction between rude and smart people." Due to the removal of numerous comments due to improper speech, twelve of the twenty-eight visible comments displayed noteworthy radical feminist characteristics.

The comparison of these two circumstances is shown in Table 2.

Table 2 Sort of Comments Comparative

\begin{tabular}{|c|c|c|}
\hline Sort of Comments & $\begin{array}{c}\text { TikTok } \\
\text { (\%) }\end{array}$ & $\begin{array}{c}\text { Weibo } \\
\text { (\%) }\end{array}$ \\
\hline $\begin{array}{c}\text { Trying to advocate for } \\
\text { female autonomy and } \\
\text { personality }\end{array}$ & 98 & 57 \\
\hline $\begin{array}{c}\text { sexist insults directed at } \\
\text { males }\end{array}$ & 3 & 43 \\
\hline
\end{tabular}

Figure 2 compares teams based on the factor "Sort of comments." The findings show that the "Tiktok" group is considerably higher than the "Weibo" category inside the "Trying to advocate for female autonomy and personality $\quad(98.00$ percentages Versus 57.10 percentages), and shown in Table 2 a following, overall variation is statistically significant.

\begin{tabular}{|c|c|c|c|c|}
\hline & \multicolumn{2}{|c|}{ Platform (N, \%) } & \multirow[t]{2}{*}{$\chi^{2}$} & \multirow[t]{2}{*}{$P$} \\
\hline & TikTok & Weibo & & \\
\hline Sort of & & & 37.49 & $<0.01$ \\
\hline \multicolumn{5}{|l|}{ Comments } \\
\hline Trying to & 98 & 16 & & \\
\hline $\begin{array}{l}\text { advocate for } \\
\text { female }\end{array}$ & (98.00\%) & (57.10\%) & & \\
\hline autonomy & & & & \\
\hline and & & & & \\
\hline personality & & & & \\
\hline sexist insults & 2 & 12 & & \\
\hline $\begin{array}{l}\text { directed at } \\
\text { males }\end{array}$ & (2.00\%) & (42.90\%) & & \\
\hline
\end{tabular}

Figure 2 Sort of Comments Comparative
Looking at the comments on feminist ideology in videos, $\mathrm{s}$ in TikTok, the radical feminist views typically argue and criticize the original video content, whilst Weibo devolved into personal assaults against men.

\section{DISCUSSIONS}

Even while the posts on social media chosen for this essay would not reflect the whole social networking site, nevertheless, certainly show the main distinctions between Western and Chinese feminism.

\subsection{Masculinity}

In contrast to radical feminism, moderate feminism may be utilized to manage the growth of feminism as a weapon against harsh situations (Roy, 2013). [23]

Johnson (2012) illustrates that in the 1980s and 1990 s, some feminists questioned women's interactions with masculine, and they investigated the metaphysical status of "women" in the debate over transsexual feminism. ${ }^{[9]}$ They do not understand what it is like to "become a woman," consequently, transgender women cannot see themselves as "feminine." This concept explains the criticism of videos on females and masculinity.

\subsection{Patriarchy}

Women are submissive to males in a patriarchal society. A female who exercises authority convincingly and with dedication will be characterized as "arrogant," while a man who acts in the same sort of way would be explained as "deciding" or "authoritative," leading men to presume that blindly following a female's orders is degrading, and disrespectfully contorted the sex differences (Graham, 1994). ${ }^{[6]}$ Women are submissive to males in a patriarchal society. Feminists argue that "patriarchy" severely impedes women's growth since patriarchal culture promotes males while restricting gender equality and empowering women (Altay, 2019). ${ }^{[1]}$ In her video, @SoniaWang discussed the harms of patriarchy and the necessity for female awareness to be awakened. Many of @thedebralea's responses questioned whether she was a feminist since she displayed patriarchal support, echoing her scepticism of radical feminism's traits. According to Altay (2019), radical feminists, in contrast, think that patriarchal is irrational and, therefore, unnecessary. ${ }^{[1]}$

\subsection{Household duties}

Women commit up to 5 times as much time as men to caring for others. Many feminists argue that the household is inextricably linked to gender discrimination since housekeeping has a monetary value, whereas many ladies are not compensated. This form of imbalance has lessened in upper-class households, although this is 
mainly due to women steadily reducing their time spent on chores rather than males increasing their time spent on cleaning (Lightman, 2021). [11] As can be seen, discussing housework is a widespread issue among feminists. @SoniaWangs believes that males and females should not be limited by gender and therefore should collaborate in the division of tasks based on their various areas of competence, but @Thedebralea still believes that females should go back to the home.

\subsection{Work}

Mackay (2015a) states that due to the international development of economic liberalism, the widespread availability of domestic has resulted in an increasing number of women leaving home to employment. ${ }^{[15]}$ The workplace continues to be a symbol of injustice, and feminism strives for wage equality and higher status. Because feminist themes have gained prominence, a notion of the happy work-life balance that supports equality, justice, and women's freedom has emerged in the United Kingdom and the United States (Rottenberg, 2019). ${ }^{[22]}$ The classical \#metoo movement, women's demonstrations, and worldwide women's striking highlight autonomous females' struggles for their ideal lifestyles. Most feminists emphasized the issue of women's employment balancing, but they both preferred to go back to the marriage based on their traits instead of being isolated from men out of need. The radical feminist statements in the remarks, on the other hand, engaged women to maintain them in societies.

\subsection{Factors of history}

The disparity between TikTok's and Weibo's radical statements on female rights is connected to China's isolation from Western Feminist ideology. Western feminist study and advancement have progressed throughout a historical development process, from discipline revolution to contemporary cultural studies, to mainstream media science. The western women's rights movement has gone through several phases, including "liberal feminism," "socialist feminism," "radical feminism," and "postmodern feminism" (Yuemin, 2008). ${ }^{[29]}$ Women in the West are more conscious of gender issues. Most TikTok comments are about women's education, salary, patriarchy, autonomy, fairness, and uniqueness. Meanwhile, @ thedebralea was chastised for believing that women should only have beauty. According to radical feminism, both females and males may be rational, peaceful, entrepreneurial, aggressive, loving, and include closeness and cooperation (Lorber, 1997). ${ }^{[14]}$ Nonetheless, extreme feminism can devolve into mindless neutralism, thinking that females, like males, ought to be career oriented as well as sexual "liberated," despite the fact that many women balances work and home life. Because of a lack of systematic shaping, the radical feminist movement has a limited background, so these "theoretical" and "utopian" notions can swiftly lead the breakdown of verification into reality (Bouchier, 1979). ${ }^{[3]}$ Fighting gender discrimination, exercising subjective initiative, decentralization, and building a diversified feminist worldview are characteristics of teenage girls expressing feminism via Weibo (Lixian, 2015). ${ }^{[12]} @$ SoniaWangs suggested several innovative and progressive concepts, such as how women and men work together based on their qualities. In opposition to TikTok, remarks on Weibo frequently name guys and make various assaults on men. That is because, in the processes of "indigenization" in China, extreme Western feminism has evolved into a violent hatred of males, implying that females should indeed be prioritized primarily due to their physical weakness (Mao, 2020). ${ }^{[17]}$ Women have been inspired to achieve equality as a result of market policies. Simultaneously, the media and the Internet have given women a wider variety of discussion alternatives, giving rise to ideal feminists who think that males should meet the various demands of women but should not be required to perform their obligations. The traits of "China Rural Feminism" that have emerged in new and ego media mostly inspire masculine enmity and hatred of males. Females only enjoy rights than taking on responsibilities, and weddings and childbirth are utilized as negotiating chips to favour women. While Chinese pastoral feminists exhibit certain traits of radical feminism, the earlier prefer female authority over male dominance and seek financial goals, and the latter desire liberty and fairness (Fan, 2020). ${ }^{[4]}$

\section{CONCLUSIONS}

This essay objectively reveals the parallels and contrasts in the representation of feminist discourse on Chinese and Western media platforms by examining the content uploaded by two feminists on the two systems. Both blogs' primary feminist ideas include masculinity, patriarchy, housekeeping, and labour. In order to articulate moderation feminism, TikTok is dedicated to combating extreme feminism, whereas Weibo is dedicated to championing gender equality. In terms of extreme feminist speech, TikTok prefers to fight for female rights, whereas Weibo contains broad anti-male sentiments. These distinctions are due to the historical traditions and structures of Chinese and Western feminist development. Nonetheless, the study in this paper has several limitations since individual blogger comments hardly symbolize the current situation of the comprehensive platform.

According to observations, bloggers' material on the two systems is still not limited to female notions and knowledge, there is also a tendency to use feminist topics as fashion topics for marketing. Furthermore, the author discovered that many views on Weibo have been censored, connected to China's tight online information 
censoring system since irrational feminism is a particularly contentious subject in China. A significant issue that related departments confront on Weibo is communicating and managing public opinion and public sentiment because Weibo users' content expression may readily develop irrational group behaviors (Jiangwei, 2019). ${ }^{[8]}$ China's newly established Government Online Scheduling Agency will direct, manage, and supervise online entertainment management and execute regulatory clearances regarding internet media coverage (Xinhuashe, 2011). ${ }^{[28]}$ TikTok's remarks, on the other hand, are not subject to Chinese government regulation, thus gender relationships accounts are not tightly restricted.

\section{REFERENCES}

[1] Altay, S. (2019). Patriarchy and Women's Subordination: A Theoretical Analysis. e-Şarkiyat İlmi Araştırmaları Dergisi/Journal of Oriental Scientific Research (JOSR). https://doi.org/10.26791/sarkiat.541704

[2] Bengtsson, M. (2016). How to plan and perform a qualitative study using content. analysis. NursingPlus Open, 2, 8-14. https://doi.org/10.1016/j.npls.2016.01.001

[3] Bouchier, D. (1979). The Deradicalization of Feminism: Ideology and utopia in action. Sociology (Oxford), 13(3), 387-402. https://doi.org/10.1177/003803857901300302

[4] Fan, Y. (2020). Alienation and Construction of Indigenous Feminism in China (Master's Thesis, East China University of Political Science and Law).

https://kns.cnki.net/KCMS/detail/detail.aspx?dbna me $=$ CMFD202101\&filename $=1021508769 . \mathrm{nh}$

[5] Flores, P., Gómez, N. R., Roa, A. F., \& Whitson, R. (2020). Reviving feminism through social media: from the classroom to online and offline public spaces. Gender and Education, 32(6), 751-766. https://doi.org/10.1080/09540253.2018.1513454

[6] Graham, G. (1994). Liberal vs Radical Feminism Revisited. Journal of Applied. Philosophy, 11(2), $155-170$.

https://doi.org/10.1111/j.1468-5930.1994.tb00105. $\mathrm{x}$

[7] Greetham, B. (2009). How to write your undergraduate dissertation. Palgrave Macmillan.

[8] Jiangwei, Hu. (2019). Research on the Communication and Management of Public Emotions on Weibo. (Doctoral Dissertation, Nanchang University).
https://kns.cnki.net/KCMS/detail/detail.aspx?dbna $\mathrm{me}=\mathrm{CDFDLAST} 2021 \&$ filename $=1020022501 . \mathrm{nh}$

[9] Johnson, K. (2012). Transgender, transsexualism, and the queering of gender identities: debates for feminist research. In Handbook of feminist research: Theory and praxis (pp. 606-626). SAGE Publications, Inc., https://www-doi-org.ezproxy.library.sydney.edu.au /10.4135/9781483384740

[10] Kaye, D. B. V., Chen, X., \& Zeng, J. (2021). The co-evolution of two Chinese mobile. short video apps: Parallel platformization of Douyin and TikTok. Mobile Media \& Communication, 9(2), 229-253.

https://doi.org/10.1177/2050157920952120

[11] Lightman, N., \& Kevins, A. (2021). "Women's Work": Welfare State Spending and the Gendered and Classed Dimensions of Unpaid Care. Gender \& Society, 35(5), 778-805. https://doi.org/10.1177/08912432211038695

[12] Lixian, H. (2015). On Fire in Weibo: Feminist Online Activism in China. Economic and Political Weekly, 50(17), 79-85.

[13] Locke, A., Lawthom, R., \& Lyons, A. (2018). Social media platforms as complex and contradictory spaces for feminisms: Visibility, opportunity, power, resistance and activism. Feminism \& Psychology, 28(1), 3-10. https://doi.org/10.1177/0959353517753973

[14] Lorber, J. (1997). The variety of feminisms and their contributions to gender equality. Oldenburg: BIS, Bibliotheks-und Informationssystem der Universität Oldenburg.

[15] Mackay, F. (2015a). Radical Feminism: Feminist Activism in Movement. Palgrave. Macmillan UK. https://doi.org/10.1057/9781137363589

[16] Mackay, F. (2015b). Radical Feminism. Theory, Culture \& Society, 32(7-8), 332-336. https://doi.org/10.1177/0263276415616682

[17] Mao, C. (2020). Feminist activism via social media in China. Asian Journal of Women's Studies, 26(2), 245-258.

https://doi.org/10.1080/12259276.2020.1767844

[18] Munro, E. (2013). Feminism: A Fourth Wave? Political Insight (Political Studies Association of the United Kingdom), 4(2), 22-25. https://doi.org/10.1111/2041-9066.12021

[19] Rebecca, N.G. \& Stefanie M.S. (2021). Retrieved 24 October 2021, from https://projekter.aau.dk/projekter/files/421099026/ master_thesis_2021_final.pdf. 
[20] Rich, E. (2005). Young women, feminist identities and neo-liberalism. Women's. Studies International Forum, 28(6), 495-508. https://doi.org/10.1016/j.wsif.2005.09.006

[21] Rivers, N. (2017). Postfeminism(s) and the Arrival of the Fourth Wave: Turning Tides. Springer International Publishing AG.

[22] Rottenberg, (2019). Women Who Work: The limits of the neoliberal feminist paradigm. Gender, Work, and Organization, 26(8), 1073-1082. https://doi.org/10.1111/gwao.12287

[23] Roy, S. (2013). Feminist 'Radicality' and 'Moderation' in Times of Crises and Change. The Sociological Review, 61(2_suppl), 100-118. https://doi.org/10.1111/1467-954X.12102

[24] Soina, W. (2021). Looking at feminism from my own perspective. Retrieved September 10, 2021, from https://weibo.com/soniasoniawangs?tabtype=newV ideo\&layerid $=4679687869040915$

[25] Thedebralea. (2021). My taken on modern day feminism. Retrieved April 27, 2021, from https://vm.tiktok.com/ZM84PhUMK/

[26] Vukoičić, J. (2017). Radical feminism as a discourse in the theory of conflict. СОЦИОЛОШКИ ДИСКУРС, 3(5). https://doi.org/10.7251/socen1305033v

[27] Wu, Y. (2014). Mistress or hero? corruption reports on sina weibo and the construction of chinese femininity (Order No. 1572504). Available from ProQuest One Academic. (1650705407). Retrieved from http://ezproxy.library.usyd.edu.au/login?url=https:/ /www.proquest.com/dissertations-theses/mistress-h ero-corruption-reports-on-sina-weibo/docview/165 $0705407 /$ se-2 ?accountid $=14757$

[28] Xinhuashe. (2011). China sets up State Internet information office. Retrieved May 4, 2011 from http://www.chinadaily.com.cn/china/2011-05/04/c ontent_12440782.htm

[29] Yuemin, W. (2008). Deconstructing Feminist Media Criticism in a Cross-cultural Context. Humanities and Social Sciences Edition (Journal of Zhejiang University), 2008, 38(4): 109-. 